\title{
Pipeline Embolization for the Treatment of a Progressively Enlarging Symptomatic Carotid Artery Petrous Segment Pseudoaneurysm: Case Report
}

Michael T. Madison ${ }^{1}$, Archie Defillo ${ }^{2}$, Jeffrey P. Lassig, Andrea M. Zelensky ${ }^{4}$, Eric S. Nussbaum ${ }^{5}$

1. National Brain Aneurysm Center, St. Joseph's Hospital, St. Paul, MN 2. St. Joseph's Hospital, National Brain Aneurysm Center 3. 4. St. Joseph's Hospital, St. Paul, MN 5. John Nasseff Neuroscience Institute, MN Neurovascular \& Skull Base Surgery, National Brain Aneurysm Center at the John Nasseff Neuroscience Institute, MN Neurovascular \& Skull Base Surgery

$\square$ Corresponding author: Archie Defillo, adefillo@healtheast.org

Disclosures can be found in Additional Information at the end of the article

\section{Abstract}

Introduction: In this report, we present the case of a young patient with a long history of a progressively enlarging internal carotid-petrous segment pseudoaneurysm (ICA-P). Surgical treatment at diagnosis was deemed untenable, and prior coil embolization of the pseudoaneurysm was unsuccessful. Upon recent reevaluation, the use of a flow diverting technique, such as the pipeline embolization device (PED), was considered a suitable option to treat the expanding lesion.

Case Report: We present the case of a 39-year-old male who presented in 2001 with a history of left-sided hearing loss and vertigo. The presenting symptoms prompted magnetic resonance imaging (MRI) imaging, initially demonstrating a 6 mm left ICA-P pseudoaneurysm. Surgical treatment was considered a high risk procedure at the time. Attempted coil embolization was unsuccessfully undertaken. Post-diagnosis follow-up magnetic resonance angiographies (MRAs) confirmed the progressive enlargement of the lesion, maximally increasing to a $16 \mathrm{~mm}$ size. Pipeline embolization was considered a reasonable treatment option.

Conclusions: The use of a PED may be a safe alternative treatment option for patients presenting with a progressively enlarging ICA-P pseudoaneurysm, which is not amenable to surgical intervention or primary coil embolization.

Received 04/17/2013

Review began 04/18/2013

Published 07/29/2013

(๑) Copyright 2013

Madison et al. This is an open access article distributed under the terms of the Creative Commons Attribution License CC-BY 3.0., which permits unrestricted use, distribution, and reproduction in any medium, provided the original author and source are credited.
Categories: Radiology, Neurosurgery

Keywords: flow-remodeling techniques, flow-diverting stents, ica-p, pipeline embolization device, petrous pseudoaneurysm, endovascular stent

\section{Introduction}

Dissecting aneurysms of the intracranial circulation are uncommon, representing only $3 \%$ of all cerebral aneurysms [1-2]. If symptomatic, enlarging, and untreated, mortality rates for patients suffering from these lesions may approach $80 \%$ within five years of diagnosis [1-2].

The endovascular use of coils and covered stents to reconstruct an incompetent arterial wall 


\section{Cureus}

and prevent life-threatening bleeds from internal carotid-petrous segment (ICA-P) pseudoaneurysms is well-documented in current literature [3-10]. However, reports on flowremodeling techniques to treat such lesions are less common. With the introduction of flowdiverting stents, treatment of aneurysms with challenging morphologies can be accomplished by eliminating or reducing wall shear stress within the sick arterial segment, while allowing flow throughout the parent artery branches and perforating arteries $[1,11-15]$.

\section{Case Presentation}

We are describing the case of a 39-year-old male who in 2001 presented with a history of leftsided hearing loss and vertigo. The presenting symptoms prompted non-invasive MRI imaging, which demonstrated a 6 mm left ICA-P segment pseudoaneurysm (Figure 1A). Surgical treatment was considered a high-risk procedure at time of initial evaluation and attempted coil embolization was unsuccessfully undertaken. Since the diagnosis, the patient has been clinically followed and MRAs confirmed the progressive enlargement of the lesion to approximately $16 \mathrm{~mm}$ in size (Figures $1 B-1 D$ ). Pipeline embolization was considered a reasonable alternative treatment option for this expanding ICA-P pseudoaneurysm.

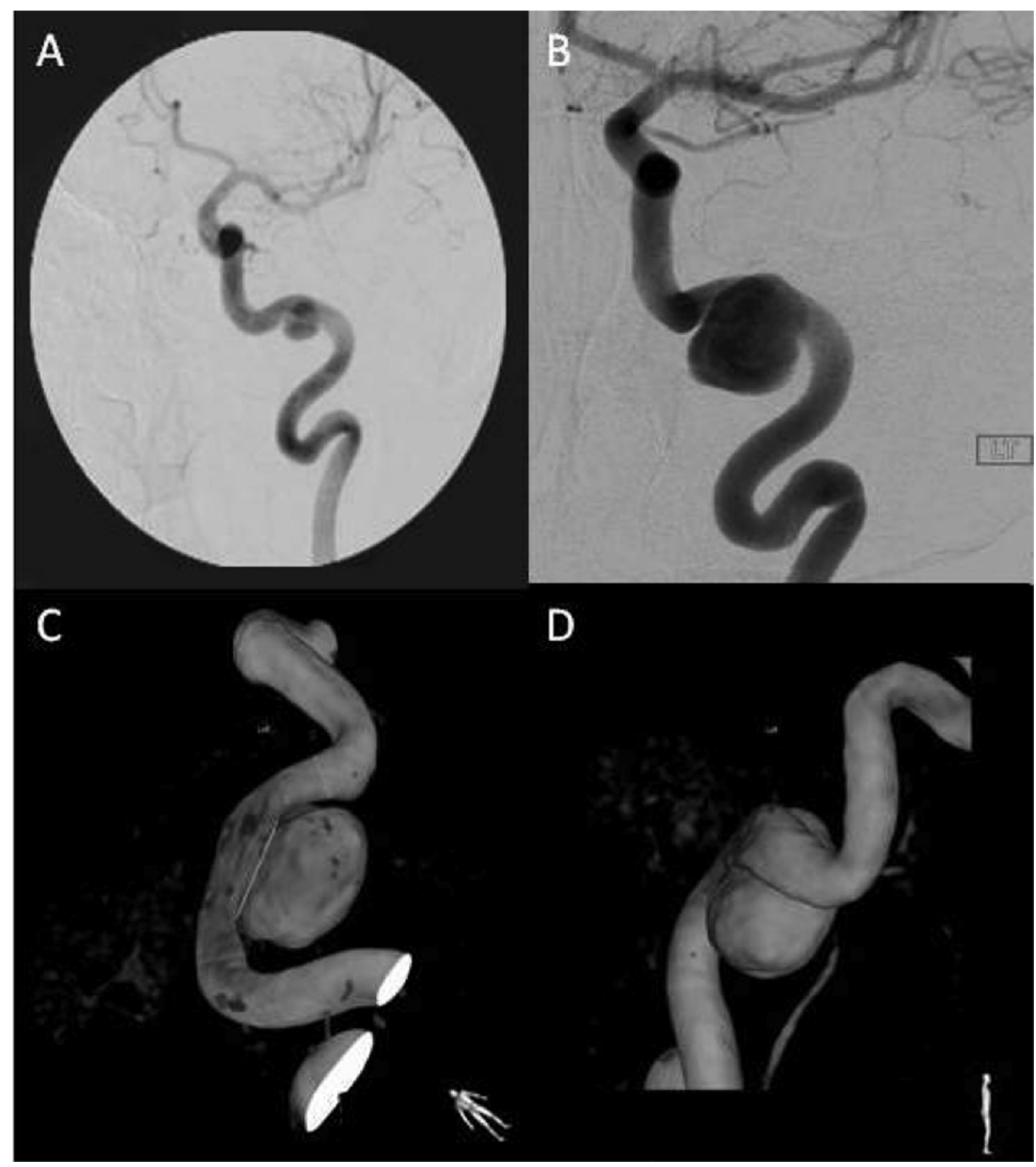

FIGURE 1: 39-year-old male who in 2001 presented with a 


\section{Cureus}

\section{history of left-sided hearing loss and vertigo}

A) Initial (2001) angiogram demonstrating a $6 \mathrm{~mm}$ wide-necked ICA-P pseudoaneurysm. B) Current angiogram viewing a progressively enlarging lesion to a $16 \mathrm{~mm}$ size. C \& D) 3D reconstruction angiography showing a wide-necked $(9 \mathrm{~mm})$ lesion associated with narrowing of the proximal vessel to the aneurysm segment, indicating a probable previous dissection.

\section{Technique description}

After placing the patient under general anesthesia with heparinization, a sub-selective catheterization of the cervical left internal carotid artery was performed using a right femoral puncture. A pre-procedure diagnostic angiogram demonstrated a 16x12x10 mm left ICA-P with a $9 \mathrm{~mm}$ neck (Figure $2 \mathrm{~A}$ ). Following the diagnostic procedure, the initial catheter was exchanged for a 6-French sheath guidewire and advanced into the left internal carotid artery (L-ICA). A reflux catheter was then advanced in a coaxial fashion and placed into the ascending petrous segment of the L-ICA. Through the long sheath and reflux catheter, a microcatheter was then advanced into the supraclinoid segment of the L-ICA. Utilizing this microcatheter, a PED was deployed from the distal petrous segment of the L-ICA into the proximal ascending ICA-P segment, positioning the device across the length of the pseudoaneurysm neck. A control angiogram showed successful stent deployment and suggestion of early stasis within the pseudoaneurysm (Figure $2 B$ ). There were no complications during the procedure. The patient was discharged home within 24 hours in satisfactory condition. A follow-up angiogram performed six months post-procedure demonstrated a complete occlusion of the lesion with a widely patent stent and normal ICA-P vasculature (Figures $2 C, 2 D$ ). 


\section{Cureus}

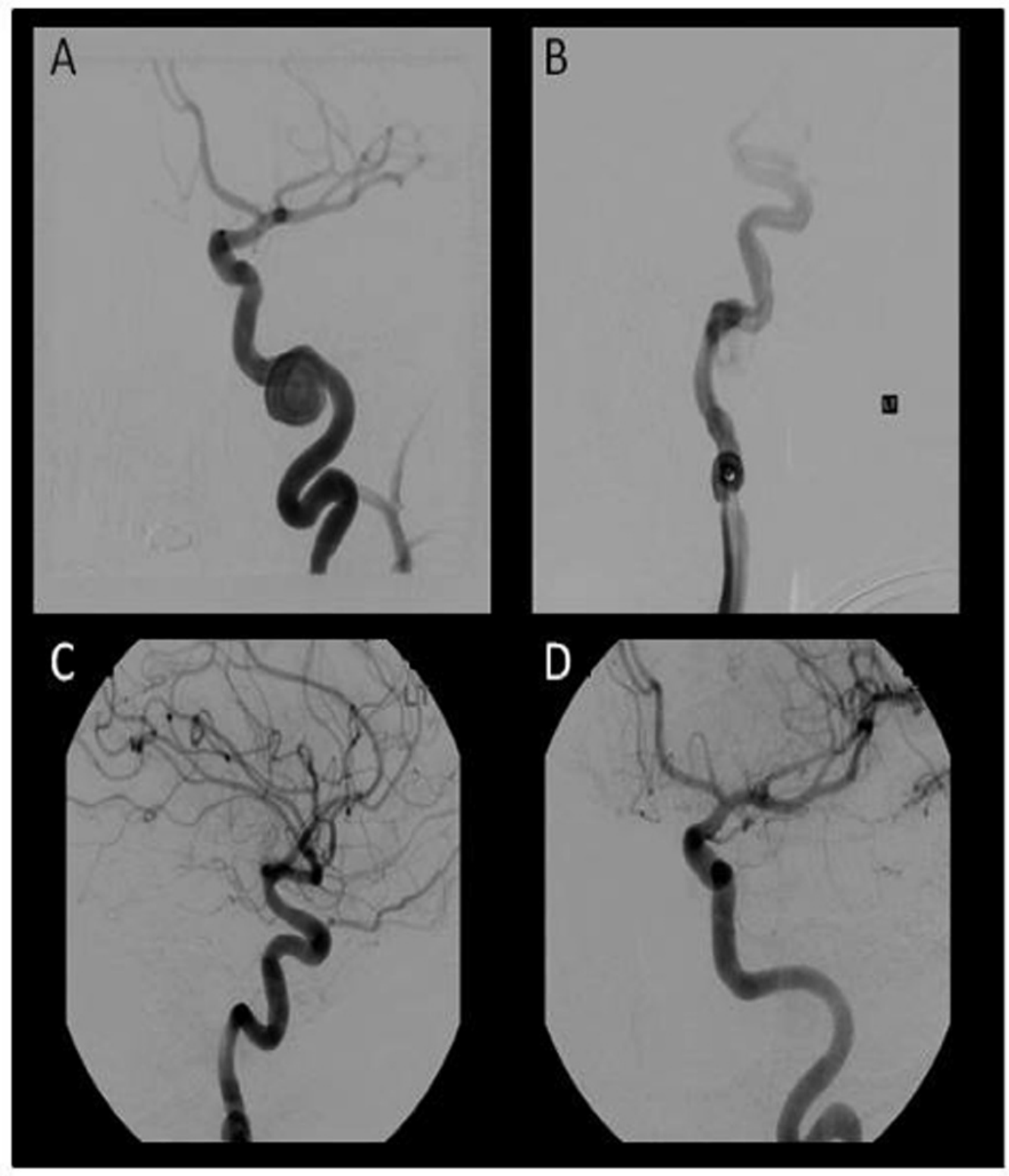

FIGURE 2: fter placing the patient under general anesthesia with heparinization, a sub-selective catheterization of the cervical left internal carotid artery was performed using a right femoral puncture.

A) Pre-embolization diagnostic angiography re-demonstrating the area of dehiscence/pseudoaneurysm, which arose primarily from the horizontal left ICA-P segment. B) Occlusion after PED stent deployment, suggesting early blood flow redistribution and stasis within the lesion. $C \&$ D) Six month follow-up angiogram showing a widely patent stent with normal ICA-P vasculature.

\section{Discussion}

Covered stents and detachable coils have been used to successfully treat iatrogenic, infective, and traumatic ICA-P pseudoaneurysm [3-10]. Endovascular stents may be the preferred method of treatment in some patients based on their ability to gradually promote arterial wall healing 
leading to closure of the weaker and incompetent arterial segment, while preserving flow through the parent artery $[3,5,16]$.

The PED was introduced in April 2011 following approval from the Food and Drug Administration. It is currently approved to treat very large wide-necked intracranial aneurysms of the internal carotid artery involving the petrous to the superior hypophyseal segments $[1,11$ 15]. The PED is a tubular, endoluminal-covered, flexible bimetallic mesh that is designed to prevent blood flow from the aneurysm while keeping the parent artery intact.

Important factors to evaluate when considering the PED as a flow-diversion technique include careful evaluation of the branching arteries and the associated perforators related to that specific arterial segment [1, 11-15]. In addition, the use of PED may be contraindicated in patients with active bacterial infection, patients who have not received dual antiplatelet agents prior to the procedure, or in whom dual antiplatelet therapy is contraindicated, and those who have a pre-existing stent in the parent artery at the target aneurysm location.

There is evidence published in the current literature to suggest PED use can be a safe and successful method of aneurysm treatment, though few studies evaluate its use in the ICA-P. A recently published series describing 23 dissecting intracranial aneurysm patients treated with PED evaluated occlusion rates and clinical outcome. In this series, most patients presented with acute subarachnoid hemorrhage (52\%), mass effect (22\%), and cerebral ischemia (4\%). Ninety-one percent of the dissecting lesions were located in the intracranial posterior circulation, with only two dissecting aneurysms found in the anterior circulation (supraclinoid ICA and proximal MCA), and none in the ICA-P segment. Higher occlusion rates were achieved in small $(<10 \mathrm{~mm})$ aneurysms, with an overall occlusion rate of $69.5 \%$. Good clinical outcome was demonstrated in $74 \%$ of patients [1].

Fiorella, et al. described the use of the PED to treat two patients who presented with large, symptomatic, circumferential, fusiform intracranial vertebral artery aneurysms. In both patients, microsurgical intervention was considered a high risk procedure, and endovascular interventions failed. Parent vessel reconstruction with aneurysm exclusion was achieved in both cases, although in one patient, adjunct coiling was added within the saccular component of the complex fusiform aneurysm. Cylindrical reconstruction and aneurysm exclusion was confirmed with angiography after 72 hours, and no further complications were reported at 30 days or one year follow-up [11].

Another report by Fiorella, et al. describes a symptomatic, large, ophthalmic segment ICA aneurysm associated with an ipsilateral dolichoectatic supraclinoid ICA and middle cerebral artery (MCA) aneurysms. Initial treatment was performed via coil embolization without stent, which provoked coil compaction and recanalization of the aneurysm. Multiple pipeline stents were used to reconstruct the anterior circulation from the distal MCA-M1 to the distal ICAcavernous segment, which led to reorganization of blood flow through the anterior cerebral and anterior choroidal arteries, resulting in complete occlusion of the aneurysm [12].

The treatment benefits of the PED in patients with ruptured aneurysms and challenging morphologies were documented in three patients with a posterior basilar trunk fusiform dilatation, a blister-like supraclinoid ICA, and an A1-A2 segment anterior cerebral artery junction dissecting aneurysm [14]. Aneurysm obliteration was achieved in all three cases with no early hemorrhage or adverse events. Although this series is small, the authors highlighted the substantial value of flow-remodeling devices in treating fusiform, giant, and wide-necked aneurysms that are not amenable to conventional treatment strategies [14].

Treatment of an iatrogenic pseudoaneurysm of the left ICA at the level of the carotid canal with 
a PED is discussed by Amenta, et al., similar to our case; flow stasis within the aneurysm dome was demonstrated after deployment of overlapping stents. A follow-up angiogram completed four months post-procedure demonstrated total wall remodeling and endoluminal reconstruction of the left ICA lumen [17].

Though success with the PED is documented, a recent report on the use of flow-diverting technique for the treatment of a petrous, mycotic pseudoaneurysm described recurrence of the bleed 12 days after deployment of the pipeline stent. The authors suggest that treatment failure was due to blood flow pressure gradients created between the parent arterial lumen and the sick pseudoaneurysm wall, possibly induced by skull-based persistent erosive osteomyelitis [18].

Finally, careful evaluation of the branching arteries and the associated perforators related to the specific arterial segment is important when considering the selection of a flow-diversion technique $[1,3,11-15,19]$. In our case, that wasn't a point of consideration due to the fact that the ICA-P segment lacks perforators and other arterial branches, with the exception of a persistent otic artery which is part of the fetal circulation and responsible for connecting this arterial segment with the posterior circulation.

\section{Conclusions}

Endovascular flow-remodeling techniques can be considered an attractive therapeutic option with acceptable risk to treat an enlarging ICA-P segment pseudoaneurysm which is not amenable to any other form of treatment.

\section{Additional Information}

\section{Disclosures}

Human subjects: All authors have confirmed that this study did not involve human participants or tissue. Conflicts of interest: In compliance with the ICMJE uniform disclosure form, all authors declare the following: Payment/services info: All authors have declared that no financial support was received from any organization for the submitted work. Financial relationships: All authors have declared that they have no financial relationships at present or within the previous three years with any organizations that might have an interest in the submitted work. Other relationships: All authors have declared that there are no other relationships or activities that could appear to have influenced the submitted work.

\section{References}

1. de Barros Faria M, Nella Castro R, Lundquist J, Scrivano E, Ceratto R, Ferrario A, Lylyk P: The role of the pipeline embolization device for the treatment of dissecting aneurysms. Am J Neuroradiol. 2011, 32:2192-2195.

2. Santos-Franco JA, Zenteno M, Lee A: Dissecting aneurysms of the vertebro-basilar system: a comprehensive review on natural history and treatment options. Neurosurg Rev. 2008, 31:131-140.

3. Alexander MJ, Smith TP, Tucci DL: Treatment of an iatrogenic petrous carotid artery pseudoaneurysm with symbiot covered stent: Technical case report. Neurosurgery. 2008, 50 : 658-662.

4. Alvernia JE, Patel RN, Cai DZ, Dang N, Anderson DW, Melgar M.Alvernia JE, Patel RN, Cai DZ, Dang N, Anderson DW, Melgar M: A successful combined endovascular and surgical treatment of a cranial base mucormycosis with an associated internal carotid artery pseudoaneurysm. Neurosurgery . 2009, 65:733-740.

5. Auyeung KM, Jui WM, Chow LCK, Chan FL: Massive epistaxis related to a petrous carotid artery pseudoaneurysm after radiation therapy: Emergency treatment with covered stent in two cases. Am J Neuroradiol . 2003, 24:1449-1452.

6. Lempert TE, Halbach VV, Higashida RT, Dowd CF, Urwin RW, Balousek PA, Hieshima GB: 
Endovascular treatment of pseudoaneurysms with electrolytically detachable coils . Am J Neuroradiol. 1998, 19:907-911.

7. Schmerber S, Vasdev A, Chahine K, Tourmaine R, Bing F: Internal carotid false aneurysm after thermocoagulation of a gasserian ganglion. Otology and Neurology . 2008, 29:673-675.

8. Schonholz C, Krajcer Z, Parodi JC, Mendaro E, Hannegan C, D’Agostino H, Selby B, Guimaraes M, Uflacker R: Stent-graft treatment of pseudoaneurysm and arteriovenous fistula in the carotid artery. Vascular. 2006, 14:123-129.

9. Telmesani LM: Ruptured petrous carotid pseudoaneurysm complicating malignant otitis media. The journal of Otolaryngology. 2004, 13:278-280.

10. Yagci AB, Ardic FN, Oran L, Bir F, Karabulut N: Ruptured petrous carotid pseudoaneurysm due to tuberculous otitis: Endovascular treatment. Interventional neuroradiology. 2006, $12: 53=56$.

11. Fiorella D, Woo HH, Alburquerque FC, Nelson PK: Definitive reconstruction of circumferential, fusiform intracranial aneurysms with the pipeline embolization device. Neurosurgery. 2008, 62:1115-1121.

12. Fiorella D, Alburquerque FC, Gonzalez F, McDougall CG, Nelson PK: Reconstruction of the right anterior circulation with a pipeline embolization device to achieve treatment of a progressively symptomatic, large carotid aneurysm. Neurointerv Surg. 2010, 2:31-37.

13. Lylyk P, Miranda C, Ceratto R, Ferrario A, Scrivano E, Luna HR, Berez AL, Tran Q, Nelson PK, Fiorella D: Curative endovascular reconstruction of cerebral aneurysms with pipeline embolization device: The Buenos Aires experience. Neurosurgery . 2009, 64:632-642 Discussion 642-643.

14. Martin AR, Cruz JP, Matouk CC, Spears J, Marotta TR: he pipeline flow-diverting stent for eclusion of ruptured intracranial aneurysms with difficult morphologies. Operative Neurosurgery. 2012, 70:21-27.

15. Nelson PK, Lylyk P, Szikora I, Wetzel SG, Wanke I, Fiorella D: The pipeline embolization device for the intracranial treatment of aneurysms trial. Am J Neuroradiol. 2011, 32:34-40.

16. Mericle RA, Lanzino G, Wakhloo AK, Guterman LR, Hopkins LN: Stenting and secondary coiling of intracranial internal carotid artery aneurysm; Technical case report. Neurosurgery. 1998, 43:1229-1234.

17. Amenta PS, Starke RM, Jabbour PM, Tjoumakaris SI, Gonzalez LF, Rosenwasser RH, Pribitkin EA, Dumont AS: Successful treatment of a traumatic carotid pseudoaneurysm with the Pipeline stent: Case report and review of the literature. Surgical Neurology International. 2012, 3:160.

18. Kadkhodayan Y, Shetty VS, Blackburn SL, Reynolds MR, Cross DT, Moran CJ: Pipeline embolization device and subsequent vessel sacrifice for treatment of a bleeding carotid pseudoaneurysm at the skull base: a case report. J Neurointerv Surg. 2012, Jul 28:[Epub ahead of print].

19. Lopes DK, Johnson AK: Evaluation of cerebral artery perforators and the pipeline embolization device using optical coherence tomography. J Neurointervent Surg. 2012, 4:291294. 